\title{
Floral Odors and the Interaction between Pollinating Ceratopogonid Midges and Cacao
}

\author{
Sarah E. J. Arnold ${ }^{1}$. Samantha J. Forbes ${ }^{2}$ - David R. Hall ${ }^{1}$ (D) Dudley I. Farman ${ }^{1}$ (D) Puran Bridgemohan $^{3}$ (D) \\ Gustavo R. Spinelli ${ }^{4}$ - Daniel P. Bray ${ }^{1}$ (D) Garvin B. Perry ${ }^{3} \cdot$ Leroy Grey $^{5} \cdot$ Steven R. Belmain $^{1}$ (D) \\ Philip C. Stevenson ${ }^{1,6}(\mathrm{D}$
}

Received: 1 May 2019 /Revised: 1 September 2019 / Accepted: 10 September 2019 / Published online: 18 November 2019

(C) The Author(s) 2019

\begin{abstract}
Most plant species depend upon insect pollination services, including many cash and subsistence crops. Plants compete to attract those insects using visual cues and floral odor which pollinators associate with a reward. The cacao tree, Theobroma cacao, has a highly specialized floral morphology permitting pollination primarily by Ceratopogonid midges. However, these insects do not depend upon cacao flowers for their life cycle, and can use other sugar sources. To understand how floral cues mediate pollination in cacao we developed a method for rearing Ceratopogonidae through several complete lifecycles to provide material for bioassays. We carried out collection and analysis of cacao floral volatiles, and identified a bouquet made up exclusively of saturated and unsaturated, straightchain hydrocarbons, which is unusual among floral odors. The most abundant components were tridecane, pentadecane, $(Z)$-7pentadecene and (Z)-8-heptadecene with a heptadecadiene and heptadecatriene as minor components. We presented adult midges, Forcipomyia sp. (subgen. Forcipomyia), Culicoides paraensis and Dasyhelea borgmeieri, with natural and synthetic cacao flower odors in choice assays. Midges showed weak attraction to the complete natural floral odor in the assay, with no significant evidence of interspecific differences. This suggests that cacao floral volatiles play a role in pollinator behavior. Midges were not attracted to a synthetic blend of the above four major components of cacao flower odor, indicating that a more complete blend is required for attraction. Our findings indicate that cacao pollination is likely facilitated by the volatile blend released by flowers, and that the system involves a generalized odor response common to different species of Ceratopogonidae.
\end{abstract}

Keywords Floral traits $\cdot$ Flower odor Cacao $\cdot$ Ceratopogonidae $\cdot$ Cocoa midges $\cdot$ Tropical agriculture $\cdot$ Behavioral ecology (Z)-7-Pentadecene $\cdot(Z)-8$-Heptadecene

\section{Introduction}

A variety of cues can be used by pollinators to select flowers, including color (Arnold et al. 2010), shape (Dafni et al. 1997),

Steven R. Belmain and Philip C. Stevenson contributed equally to this work.

Electronic supplementary material The online version of this article (https://doi.org/10.1007/s10886-019-01118-9) contains supplementary material, which is available to authorized users.

Sarah E. J. Arnold

s.e.j.arnold@greenwich.ac.uk

1 Natural Resources Institute, University of Greenwich, Central Avenue, Chatham Maritime, Kent ME4 4TB, UK

2 Centre for Tropical Environmental and Sustainability Science, College of Science and Engineering, James Cook University, Cairns, Queensland, Australia pattern (Van Kleunen et al. 2007), temperature (Dyer et al. 2006), and odor (Raguso 2008; Schiestl 2010). Floral characteristics such as odor can evolve in order to favor more efficient pollinators over less efficient ones. For example,
3 Biosciences, Agriculture and Food Technologies, University of Trinidad and Tobago, Caroni North Bank Road, Arima, Trinidad and Tobago

4 División Entomología, Museo de La Plata, Paseo del Bosque s/n, 1900 La Plata, Argentina

5 Cocoa Industry Board of Jamaica, Marcus Garvey Drive, Kingston, Jamaica

6 Royal Botanic Gardens, Kew, Richmond, Surrey TW9 3AB, UK 
Mimulus lewisii Pursh emits D-limonene, $\beta$-myrcene, and $(E)$ - $\beta$-ocimene, a blend which attracts bumblebees preferentially. Conversely, its sister species M. cardinalis Douglas ex. Benth emits very low levels of these compounds and receives few bumblebee visits, but is readily pollinated by hummingbirds (Byers et al. 2014a, b). The odor blend thus serves as a selective filter to pollinators, increasing pollination efficacy.

One flower with a specialized morphology is that produced by the cacao tree, Theobroma cacao L. (Malvaceae). The small flowers have the anthers concealed within tiny, cupshaped "petal hoods", making the pollen inaccessible to larger pollinators, while the pistil is surrounded by long, usually dark red, staminodes (Supplementary Material Fig. S1). Compared to many crops such as temperate soft- and top-fruit, the plantpollinator interactions in this crop species are relatively poorly understood. This lack of knowledge persists despite cacao's global importance that stems from its widespread cultivation across the tropics as the source of cocoa. Pollination rates in cacao are often low (Forbes and Northfield 2017; Groeneveld et al. 2010) and yields are poor in many countries.

The insect pollinators of cultivated varieties of cacao are generally thought to be midges in the family Ceratopogonidae (Ceratopogonidae previously recorded visiting cacao flowers will henceforth be termed "cocoa midges" for ease), with different species performing this service in different regions (Winder 1978a). The reasons for visiting the flowers remain unclear, but access to flowers increases female longevity (Saunders 1959). Wherever cacao has been introduced, native midge species are recorded visiting the flowers, and where inspected, transferring pollen (O'Doherty and Zoll 2012). In locations where multiple midge species are present, e.g. Ghana (Kaufmann 1975), the Caribbean (Arnold et al. 2018), Costa Rica, and Brazil (Winder 1977), evidence is often limited as to which are the most efficient pollinators. A secondary pollination service may be contributed by other small Diptera (Kaufmann 1973; Winder 1978b), but there is less evidence of the importance of non-ceratopogonid flies on most plantations. Recent studies of wild trees also indicate high levels of visitation by small Hymenoptera, such as chalcid wasps (Chumacero de Schawe et al. 2018), but there is little evidence of this occurring to a large extent in cultivated systems (Frimpong et al. 2009; Winder 1978a). The midgecacao pollination system is of particular interest because different life stages of Ceratopogonidae can make use of different parts of the same cacao plant: adults benefit from visits to the flowers, while larvae can develop in discarded rotting cacao pods (Winder 1978a). Nonetheless, with the exception of some limited studies (Brew 1987; Erickson et al. 1987; Young et al. 1989), there remains a lack of knowledge about the mechanisms mediating the midgeflower interactions, particularly the cues inducing midges to land on and enter flowers.
Only a small number of studies have examined the odor bouquet of cacao flowers. In studies from Costa Rica, Erickson et al. (1987) and Young and Severson (1994) reported 1-pentadecene, $n$-pentadecane and 1-heptadecene as major components. However, the authors were unable to demonstrate that these compounds mediated any behavioral responses of the main pollinating taxon (Diptera: Ceratopogonidae) in the field (Young et al. 1989). Cacaovisiting midges have proven very difficult to rear in the laboratory across multiple generations (Saunders 1959), making controlled behavioral studies difficult or impossible.

In this study we describe the volatile compounds sampled from flowers of cacao plants from farms in the Caribbean. We report a methodology that resulted in reliable emergence of ceratopogonid midges for several months in a laboratory environment, providing sufficient adults for bioassays. We describe the results of controlled choice-tests in a Y-tube olfactometer using cocoa midges, in which adult females were allowed to choose between control odors or natural and synthetic odors of cacao flowers to test whether cacao floral volatiles are attractive to the midges and whether a synthetic blend could elicit comparable behaviors.

\section{Methods and Materials}

\section{Sampling Floral Odors}

Odors were sampled from cacao trees of Imperial Mixed Calabacillo (IMC) and Trinidad Selected Hybrid (TSH) cultivars. The trees were located on farms in St Mary Parish, Jamaica ( $\left.18^{\circ} 13^{\prime} 59^{\prime \prime} \mathrm{N} 76^{\circ} 52^{\prime} 55^{\prime \prime} \mathrm{W}\right)$, and Gran Couva $\left(10^{\circ} 25^{\prime} 17^{\prime \prime} \mathrm{N} 61^{\circ} 20^{\prime} 8^{\prime \prime} \mathrm{W}\right)$ and La Réunion $\left(10^{\circ} 35^{\prime} 30^{\prime \prime}\right.$ $\mathrm{N} 61^{\circ} 18^{\prime} 15^{\prime} \mathrm{W}$ ), Trinidad and Tobago (Arnold et al. 2018). Sampling took place in Trinidad in 2012 and Jamaica in 2013, providing samples from both the wet and dry seasons (Supplementary Material Table S1).

Cacao trees are cauliflorous with flowers emerging from flower cushions directly on the trunk and branches. Accessible branches or trunk sections with 1-4 open, fresh flowers were selected for sampling, and comparable sections without flowers were also sampled. These sections, approximately $20 \mathrm{~cm}$ long, were enclosed in a poly(ethyleneterephthalate) oven bag $(37 \times 25 \mathrm{~cm} \times 12 \mu \mathrm{m}$ thick; J Sainsbury plc, UK $)$ (Stewart-Jones and Poppy 2006). The oven bags had been previously tested for volatile emissions and determined to be odorless. Two battery-powered pumps (NMP 830 KNDC-B; KNF Neuberger, Freiburg, Germany) were used, one to pump charcoal-filtered air through Teflon tubing $(1.6 \mathrm{~mm}$ i.d. $\times$ $3.2 \mathrm{~mm}$ o.d.) into the bag $\left(600 \mathrm{~cm}^{3} \mathrm{~min}^{-1}\right)$ and the other to draw air out of the bag $\left(500 \mathrm{~cm}^{3} \mathrm{~min}^{-1}\right)$ through a collection filter, thus maintaining a positive pressure in the bag to avoid introduction of impurities. Collection filters consisted of a 
Pasteur pipette (4 mm i.d.) containing Porapak Q (200 mg, 50-80 mesh; Supelco, Gillingham, Dorset, UK) held between plugs of silanized glass wool. The Porapak Q was purified by Soxhlet extraction with dichloromethane (Pesticide Residue Grade, Fisher Scientific, Loughborough, UK) for $8 \mathrm{hr}$ and washing with dichloromethane before use. Cacao flowers ordinarily commence anthesis in late afternoon/evening, are fully open from early in the morning the following day, and remain receptive into the afternoon (Sampayan 1966). They senesce over the following 24-48 hr (Aneja et al. 1999). Volatiles were collected for $24 \mathrm{hr}$, starting at 09:00-12:00, after which collection filters were wrapped in aluminum foil and transported to the Natural Resources Institute (NRI), Chatham Maritime, UK. Volatiles were eluted with dichloromethane $(1 \mathrm{ml})$ and samples stored at $-20^{\circ} \mathrm{C}$ until analysis.

\section{Chemical Analyses}

Samples were initially analyzed on an Agilent 6890 gas chromatograph (GC) coupled to an Agilent 5973 mass spectrometer (MS) (Agilent Technologies, Manchester, UK) fitted with a fused silica capillary column $(30 \mathrm{~m} \times 0.25 \mathrm{~mm}$ i.d. $\times$ $0.25 \mu \mathrm{m}$ film thickness) coated with DB-5 (Agilent). Carrier gas was helium $\left(1 \mathrm{ml} \mathrm{min}^{-1}\right)$, injection was splitless $\left(220^{\circ} \mathrm{C}\right)$ and the oven temperature was held at $50^{\circ} \mathrm{C}$ for $2 \mathrm{~min}$, then heated to $250{ }^{\circ} \mathrm{C}$ at $6{ }^{\circ} \mathrm{C} \mathrm{min}^{-1}$ and held for $5 \mathrm{~min}$. The ion source was held at $230^{\circ} \mathrm{C}$, and the transfer line was at $250^{\circ} \mathrm{C}$.

Compound identifications were confirmed by analyses on a polar GC column using a Varian CP-3800 GC coupled directly to a Saturn 2200 MS (Varian, now Agilent). This was fitted with two fused silica capillary columns $(30 \mathrm{~m} \times 0.25 \mathrm{~mm}$ i.d. $\times 0.25 \mu \mathrm{m}$ film thickness) coated with polar DBWax (Agilent) and non-polar VF5 (Varian) respectively, and a column switching device. Carrier gas was helium $\left(1 \mathrm{ml} \mathrm{min}^{-1}\right)$, injection was splitless $\left(220^{\circ} \mathrm{C}\right.$ and $250{ }^{\circ} \mathrm{C}$ respectively) and oven temperature was held at $40^{\circ} \mathrm{C}$ for $2 \mathrm{~min}$ then programmed at $10{ }^{\circ} \mathrm{C} \mathrm{min}{ }^{1}$ to $250{ }^{\circ} \mathrm{C}$ and held for $5 \mathrm{~min}$.

Retention indices of compounds were calculated from their retention times relative to those of $n$-alkanes analyzed under the same conditions. Compounds were identified by comparison of their mass spectra and retention indices relative to those of authentic synthesized standards on both columns.

Positions of double bonds in unsaturated compounds were determined by GC-MS analyses of their dimethyl disulfide (DMDS) derivatives (Buser et al. 1983; Carlson et al. 1989). An aliquot $(100 \mu \mathrm{l})$ of a collection of volatiles estimated to contain approximately $1 \mu \mathrm{g}$ of the major alkene was evaporated just to dryness under a gentle stream of nitrogen and then treated with dimethyl disulfide $(10 \mu \mathrm{l}$; SigmaAldrich, Gillingham, Dorset, UK) and a 5\% solution of iodine in diethyl ether $(10 \mu \mathrm{l})$ in a sealed vial. After heating at $40{ }^{\circ} \mathrm{C}$ for $4 \mathrm{hr}$ the mixture was dissolved in hexane $(100 \mu \mathrm{l})$ and extracted twice with 5\% aqueous sodium thiosulfate solution
$(100 \mu \mathrm{l})$ before analysis by GC-MS on the VF5 column above.

\section{Synthetic Compounds}

Tridecane, tetradecane, pentadecane, hexadecane, heptadecane and 1-pentadecene were purchased from SigmaAldrich.

(Z)-7-Pentadecene and (Z)-8-heptadecene were synthesized by Wittig reaction between octyl(triphenylphosphonium) bromide and freshly-distilled heptanal or nonanal, respectively, with potassium $t$-butoxide in tetrahydrofuran at $0{ }^{\circ} \mathrm{C}$. Products were purified by flash chromatography on silica gel in hexane followed by kugelrohr distillation, and were $98 \%$ chemically pure $(95 \%$ isomerically pure, with approximately $5 \%$ of the $(E)$-isomers).

$(Z, Z)-6,9$-Heptadecadiene and $(Z, Z, Z)-3,6,9$-heptadecatriene were synthesized by decarboxylation of linoleic acid $((Z, Z)$ 9,12-octadecadienoic acid) and linolenic acid ((Z,Z,Z)-9,12,15octadecatrienoic acid) respectively, and characterized according to van der Klis et al. (2011). Yields were low (approx 10\%), as reported by van der Klis et al. (2011), but purities were remarkably high (> 97\% by GC analysis) after flash chromatography and kugelrohr distillation.

\section{Collection of Cocoa Midges}

Ceratopogonid cocoa midges were obtained from detritus materials (rotting cacao pods, banana pseudostem) collected from a plantation in Gran Couva, Trinidad, $\left(10^{\circ} 25^{\prime} 17^{\prime \prime} \mathrm{N}, 61^{\circ} 20^{\prime}\right.$ $\left.8^{\prime \prime} \mathrm{W}\right)$. The detritus was brought to an insectary facility at the University of Trinidad and Tobago and placed in emergence cages $(N=10,475 \times 475 \mathrm{~mm}$ Bugdorm, Taichung, Taiwan) under ambient conditions. The cages were misted with $10 \%$ sucrose solution 3-4 times per week and slices of organic apple were provided for moisture and sugar.

To encourage pupal eclosion prior to midge collection (approximately 6 weeks after the commencement of rearing), the detritus was heavily wetted with $250 \mathrm{ml}$ distilled water per cage, resulting in high pupal eclosion rates approximately two days later. Collections were conducted using a mouthoperated aspirator (pooter) to transfer midges into collection tubes lined with dampened filter paper (10\% sucrose solution in water) and sealed with cheesecloth material to permit air diffusion. In total, around 500 adult Ceratopogonidae were collected over two days. Larvae and pupae were also observed in the detritus by visual inspection, collected using fine forceps and transferred into collection vials, also totaling around 500 individuals between 10 vials. Each vial was provisioned with a "cacao substrate ball", made from rotting cacao husk rolled into a $10-15 \mathrm{~g}$ ball, to provide food and habitat for developing larvae during transit. The adults, larvae and around 250 pupae were then transported to NRI, UK, in October 2015. A second collection of larvae and pupae was 
made in March 2016 and added to the culture to boost populations.

Upon arrival in the UK, midges and detritus materials were transferred to smaller cages $(300 \times 300 \times 300 \mathrm{~mm})$ in a controlled temperature room $\left(26^{\circ} \mathrm{C}\right.$ and $60 \% \mathrm{RH}$ and a $14: 10 \mathrm{~L}: \mathrm{D}$ cycle). Each cage was placed completely within a large transparent polythene bag to retain moisture, which was secured with an elastic band. High mortality of adults was observed in the 1-2 days following transit, but larvae/pupae survived transit better. Maintenance proceeded as previously, and the cages were provided with damp leaf litter and rotten pumpkin as potential breeding sites.

The three main species in this experiment were Dasyhelea borgmeieri Wirth, Culicoides paraenesis Goeldi and Forcipomyia sp. Meigen. Specimens of all three species were identified at the Museo de La Plata by a Ceratopogonidae specialist (GRS) using morphological species descriptions and taxonomic keys for neotropical Ceratopogonidae.

Cacao pod could not be obtained in the UK, but the three main species in this experiment have been previously reported from a variety of decomposing vegetable material including leaf litter and plant detritus (Winder 1978a). The walls of the cage and the inside of the polythene bag were inspected daily to monitor for emergence.

\section{Olfactometry}

The olfactometry study aimed to characterize the responses of cocoa midges to both natural cacao flower odors and a synthetic blend. Individuals were used only once for an experiment. While the insects were kept in mixed-sex cages, males were infrequently recorded and since individuals were typically tested soon after emergence, it is possible that not all the females were mated. However, as rearing was difficult and little is known about the mating ecology of the species tested, it was not feasible to eclose adults singly and force mating before the tests. Nevertheless, unmated and mated females both need to sugar-feed and therefore were expected to exhibit similar behaviors in response to floral odors.

Sex was determined by inspection of antennae using a hand lens: male Ceratopogonidae have plumed antennae resembling a fine paintbrush and females have simple antennae with short hairs only (Borkent and Spinelli 2007). As females are reported to be the major pollinators (Winder 1978a), the availability of predominantly females was considered not to affect the ecological relevance of this study. In total, 156 female ceratopogonid individuals were trialed. We elected not to test male individuals because very few were observed in culture cages. Individual adult females of Dasyhelea borgmeieri Wirth (throughout) and Culicoides paraenesis Goeldi/ Forcipomyia sp. Meigen (during the first month) were thus collected within a week of emergence for trials by capturing them inside a pipette tip (Supplementary Material Fig. S2). In total, 66 females of three different species were tested for their preference between natural odor or solvent control: four of Forcipomyia sp., 19 of C. paraensis and 43 of $D$. borgmeieri. A further 90 females of $D$. borgmeieri only (as this species was most numerous in the culture) were trialed against synthetic odors versus solvent control, of which 44 were tested using the natural equivalent concentration (synthetic cacao floral odour, "SCFO 100\%") and 46 at $10 \%$ of this concentration ("SCFO 10\%").

Individuals were tested singly in a glass Y-tube olfactometer (Supplementary Material Fig. S3) (arm length $70 \mathrm{~mm}$, angle between the arms $120^{\circ}, 8 \mathrm{~mm}$ i.d.). Air was pushed by a pump (FB65540, Fisher Scientific) through a charcoal filter (1) to remove volatile contaminants. The airstream was then split (2) and passed through two gas-wash bottles (3), one containing the stimulus and the other the solvent control, and then into each of the two arms of the olfactometer (4), at a flow rate of $100 \mathrm{~cm}^{3} \mathrm{~min}^{-1}$ through each arm. The two arms met and merged (5) ("decision point") into the third arm of the apparatus (6) ("approach arm"). Components were connected with Tygon tubing (internal i.d. 8 or $6 \mathrm{~mm}$; Saint-Gobain, Paris, France). A lamp positioned centrally between the two arms illuminated the whole setup as Ceratopogonidae are strongly positively phototactic (Blackwell et al. 1994). The entire apparatus was shrouded by black plastic on three sides and the top to minimize visual distractions.

Individual insects were introduced into the approach arm of the olfactometer using an adapted pipette tip plugged with cotton wool; they left this readily and proceeded towards the decision point. The approach arm was then covered with dark plastic to discourage the midges from returning to the start point and leaving the apparatus. A decision was recorded when the insect entered one or the other arm of the olfactometer, and the time taken by the insect from the pipette tip to decision point was also noted. If the insect did not make a decision within $10 \mathrm{~min}$, the trial was terminated and the insect excluded from analysis.

Tests were carried out between 09:00 and 12:00, as preliminary experiments indicated that midges tested after 12:00 were less likely to make a decision within the 10 min observation period. Observations of ceratopogonid midges associated with cacao flowers in the field have, similarly, observed an activity peak in the morning (Frimpong et al. 2009). Tests were performed at $26^{\circ} \mathrm{C}$ and $60 \% \mathrm{RH}$.

For bioassays, the collection of cacao flower volatiles containing most material was used. This was estimated to contain

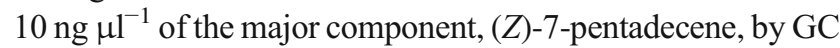
analysis in comparison with analyses of known concentrations of the synthetic compound. For the synthetic cacao flower odor (SCFO), a blend of the four major components of cacao floral odor was prepared, containing tridecane, pentadecane, (Z)-7-pentadecene and (Z)-8-heptadecene in 0.5: 1: 1: 0.5 ratio, in dichloromethane like the collection of natural flower 
volatiles. This was tested at two concentrations, one with the (Z)-7-pentadecene at $10 \mathrm{ng} \mu^{-1}$ (SCFO 100\%), making it equivalent to natural odor intensity, and after the second after dilution $\times 10($ SCFO 10\%).

For each test, an odor solution or a dichloromethane blank (solvent control) $(10 \mu \mathrm{l})$ was pipetted onto a $20 \mathrm{~mm}$ diameter filter paper in the gas-wash bottle (preliminary experiments with $1 \mu \mathrm{l}$ of stimulus did not provoke a response). After every fifth trial, odor stimuli were replaced, and stimuli and control bottle positions were switched. After every 8-10 individuals, the Y-tube apparatus was flushed through with industrial methylated spirits (IMS; denatured ethanol) and allowed to air-dry to remove any odor cues from previous midges.

\section{Statistics}

For each floral odor stimulus (natural floral odor, SCFO $100 \%$, SCFO 10\%) tested in the olfactometer assays, differences in the number of midges choosing stimulus versus control were analyzed for significance using a binomial test. $X^{2}$ tests were used to determine whether there were differences among the three genera of Ceratopogonidae in their preference for the odor stimulus over control, when tested against natural cacao floral odor. A partial correlation, controlling for the identity of the odor blend, was also performed, to evaluate whether there was a within-day effect on midges' preferences. The correlation evaluated the relationship between the number of trials since the last cleaning of the Y-tube ("trial stage"), and the probability of a midge at a given trial stage choosing the odor. All tests were performed in SPSS version 23 (IBM Corp., NY, USA).

\section{Results}

\section{Analysis of Floral Volatiles}

During 2012, volatiles were collected from three samples with flowers and one with bark only. In 2013, collections were made from 10 flower samples and eight with bark only. Collections were analyzed by GC-MS and only those made from cacao flowers contained reliably quantifiable amounts of volatile compounds. These were identified as a series of saturated and unsaturated, straight-chain hydrocarbons (Fig. 1, Table 1; Supplementary Material Fig. S4, S5). The main components were tridecane, pentadecane, a mono-unsaturated 15carbon and a mono-unsaturated 17-carbon hydrocarbon. Mono-unsaturated 13-carbon, 14-carbon and 16-carbon hydrocarbons were also detected. The mono-unsaturated hydrocarbons were characterized by their GC retention indices (Table 1) and their mass spectra, showing small molecular ions $(\mathrm{m} / \mathrm{z} 210$ and 238 for the 15- and 17-carbon compounds, respectively), and major ions at $m / z 138,125,111,97,83,69$,

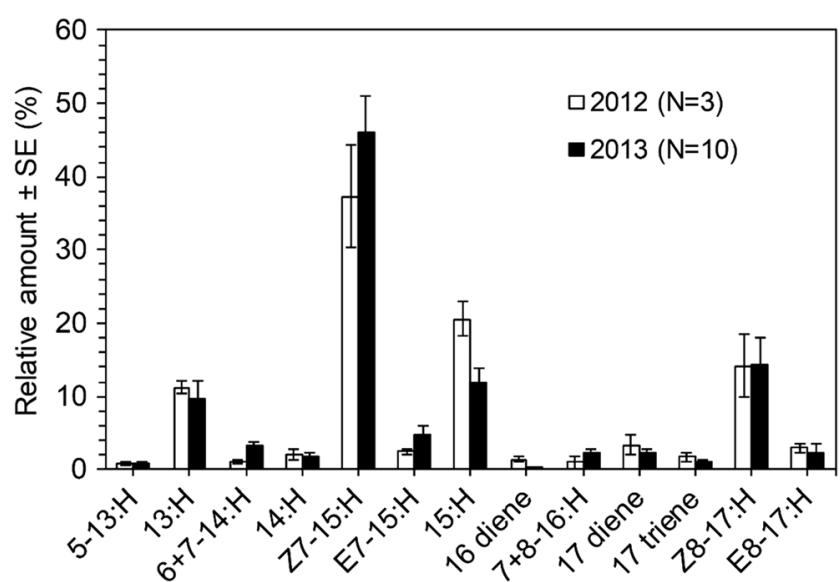

Fig. 1 Relative amounts of compounds present in volatile collections from cacao flowers, from GC-MS analyses on a non-polar DB5 GC column (the amounts of 17-triene were determined from analyses on a polar DBWax column; compound abbreviations: 5-13:H 5-tridecene; 13:H tridecane; 6+7-14:H 6- and 7-tetradecene; 14:H tetradecane; Z7-15:H (Z)-7-pentadecene; E7-15:H (E)-7-pentadecene; 15:H pentadecane; 16 diene diunsaturated 16-carbon hydrocarbon; $7+8$ 16:H 7- and 8-hexadecene; 17 diene diunsaturated 17-carbon hydrocarbon; 17 triene triunsaturated 17-carbon hydrocarbon; Z8-17:H (Z)-8heptadecene; E8-17:H (E)-8-heptadecene)

55 (Supplementary Material Fig. S6). Traces of di-unsaturated 16-carbon and 17-carbon hydrocarbons (molecular ions at $\mathrm{m} / \mathrm{z}$ 222 and 236, respectively, other ions at $\mathrm{m} / \mathrm{z} 138,123,109,95$, 81, 67 (base peak); Supplementary Material Fig. S7) were detected, as was a tri-unsaturated 17-carbon hydrocarbon (molecular ion at $\mathrm{m} / \mathrm{z} 234$, other ions at $\mathrm{m} / \mathrm{z} 135,121,108,93,79$ (base peak), 67; Supplementary Material Fig. S7).

GC-MS analysis of the derivatives resulting from the reaction of a representative collection of volatiles with dimethyldisulfide (DMDS) showed the two major mono-unsaturated compounds were 7-pentadecene and 8-heptadecene respectively (Table 1, Supplementary Material Fig. S8). Comparison of retention indices with those of synthetic standards on both non-polar and polar $\mathrm{GC}$ columns confirmed that they were mainly the (Z)-isomers, but approximately $5 \%$ of the corresponding $(E)$-isomers were also present, as evident in analyses of both underivatized and derivatized samples (Table 1, Supplementary Material Fig. S4).

The above GC-MS analyses of the collection of cacao flower volatiles treated with DMDS showed derivatives with GC retention times and mass spectra (Table 1) indicating that the 13-carbon mono-unsaturated hydrocarbon was the 5-isomer, the 14-carbon homologue was a mixture of approximately equal quantities of the 6- and 7-isomers, and the 16-carbon homologue was a mixture of the 7 - and 8-isomers.

1-Pentadecene was reported to be the major component of volatiles from cacao flowers by Erickson et al. (1987) and Young and Severson (1994). This compound had a similar mass spectrum to that of the major, mono-unsaturated 15-carbon hydrocarbon present in our volatile collections (Supplementary Material Fig. S6), but it had clearly different 
Table 1 Compounds identified in volatiles from cacao flowers and their $\mathrm{GC}$ retention indices (RI) on non-polar DB5 and polar DBWax columns, with retention indices and characteristic mass spectral ions of the dimethyldisulfide (DMDS) derivatives of unsaturated compounds

\begin{tabular}{|c|c|c|c|c|c|}
\hline & \multirow[b]{2}{*}{ Compound $^{\mathrm{a}}$} & \multicolumn{2}{|c|}{ Retention Index (RI) } & \multicolumn{2}{|c|}{ DMDS Derivative } \\
\hline & & DB5 & DBWax & RI (VF5) & Ions $(m / z)$ \\
\hline 1 & $5-13: \mathrm{H}$ & 1291 & 1321 & 1929 & $117,159,276$ \\
\hline 2 & $13: \mathrm{H}$ & 1300 & 1300 & & \\
\hline 3 & $6-14: \mathrm{H}$ & 1382 & 1426 & 2022 & $131,159,290$ \\
\hline 4 & $7-14: \mathrm{H}$ & 1384 & 1426 & 2019 & 145,290 \\
\hline 5 & $14: \mathrm{H}$ & 1400 & 1400 & & \\
\hline 6 & $\mathrm{Z} 7-15: \mathrm{H}$ & 1485 & 1521 & 2118 & $145,159,304$ \\
\hline 7 & E7-15:H & 1488 & 1521 & 2132 & $145,159,304$ \\
\hline 8 & $15: \mathrm{H}$ & 1500 & 1500 & & \\
\hline 9 & 16 diene & 1576 & 1659 & $\mathrm{ND}^{\mathrm{b}}$ & \\
\hline 10 & $7-16: \mathrm{H}$ & 1580 & 1619 & 2218 & 159,318 \\
\hline 11 & $8-16: \mathrm{H}$ & 1582 & 1619 & 2218 & $145,173,318$ \\
\hline 12 & 17 diene & 1674 & 1758 & 2296 & 131,$199 ; 159,171 ; 235,282$ \\
\hline 13 & 17 triene & 1679 & 1813 & $\mathrm{ND}^{\mathrm{b}}$ & \\
\hline 14 & $\mathrm{Z} 8-17: \mathrm{H}$ & 1681 & 1719 & 2314 & $159,173,332$ \\
\hline 15 & E8-17:H & 1687 & 1719 & 2323 & $159,173,332$ \\
\hline
\end{tabular}

${ }^{a}$ Compounds numbered according to elution order on DB5 column; abbreviations: 13:H tridecane; Z5-13:H (Z)5-tridecene; 17 diene diunsaturated 17-carbon hydrocarbon; 17 triene triunsaturated 17-carbon hydrocarbon; etc. (see Fig. 1)

b $N D$ not detected
GC retention indices on both non-polar and polar GC columns (1495 on DB5 and 1546 on DBWax) and the DMDS derivative had a different retention index (2288 on VF5) and fragmentation pattern $(m / z, 243,304)$ (Table 1 , Supplementary Material Fig. S8). 1-Pentadecene could not be detected in any of the collections of volatiles $(<0.1 \%$ of $(Z)-7$ pentadecene).

The di-unsaturated, 17-carbon hydrocarbon had identical retention times on both non-polar and polar GC columns (Table 1) and mass spectrum (Supplementary Material Fig. S7) to that of authentic $(Z, Z)-6,9$-heptadecadiene. Although other isomers were not available for comparison, the di-unsaturated, 17-carbon compound in the cacao flower volatiles is proposed to be $(Z, Z)-6,9$-heptadecadiene. The di-unsaturated 16 -carbon compound is thus inferred to be $(Z, Z)-6,9$ hexadecadiene.

Similarly, the tri-unsaturated 17-carbon hydrocarbon had identical retention times on both non-polar and polar GC columns (Table 1) and mass spectrum (Supplementary Material Fig. S7) to that of authentic $(Z, Z, Z)-3,6,9$-heptadecatriene. Although other isomers were not available for comparison, the tri-unsaturated, 17-carbon compound in the cacao flower volatiles is proposed to be $(Z, Z, Z)-3,6,9$-heptadecatriene.

\section{Midge Rearing and Olfactometry}

Three Ceratopogonidae species were recorded emerging from detritus: Dasyhelea borgmeieri, Forcipomyia (undetermined species of subgenus Forcipomyia) and Culicoides paraensis (Supplementary Material Fig. S2). Adults of D. borgmeieri continued to emerge intermittently until May 2016 (6 months after initial transport to UK), with emergence peaks indicating a generation time of around one month.

In the Y-tube bioassays there were no significant differences among the three species in the proportion of individuals choosing the natural cacao odor over the control (26/43, 14/ 19, 3/4 for D. borgmeieri, C. paraensis, F. sp. respectively; chi square test, $\left.X^{2}=1.20, d f=2, P=0.550\right)$. Overall, significantly more midges across the three species pooled $(43 / 66 ; 65.1 \%)$ chose natural cacao flower odor over the solvent control (binomial, $N=66, P=0.019$ ) (Fig. 2). Individually, $C$. paraensis significantly preferred the natural odour blend to the control (binomial, $N=19, P=0.0033$ ), whereas $D$. borgmeieri showed a non-significant preference overall (binomial, $\mathrm{N}=$ $19, P=0.111$ ), but with a generation-dependent pattern (Supplementary Material Fig. S9). Conversely, the number of $D$. borgmeieri choosing the synthetic blend of cacao floral odors compared to the solvent control did not differ significantly and did not change with time: $38.6 \%$ (17/44) chose the SCFO $100 \%$ odor blend (binomial, $N=44, P=0.174$ ) and $47.8 \%(22 / 46)$ chose the SCFO blend at $10 \%$ concentration (binomial, $N=46, P=0.883$ ) (Fig. 2). There was no clear or significant effect of number of previous trials since last washing of Y-tube on the choice behavior (Supplementary Material Fig. S10) (partial correlation controlling for odor blend, $P=$ 0.427). 


\section{Discussion}

The volatiles from cacao flowers can, alongside other stimuli, play an important role in mediating attraction of flower visitors and subsequently pollination. We sought to explore the interaction between the odor of cacao flowers and some of the insects that pollinate them. We reared ceratopogonid midges over multiple generations, and, by testing them in a binary choice assay in Y-tube olfactometer, determined that there was a weak positive response to the natural odor of cacao flowers in some species (particularly C. paraenesis). Our data indicate that the odors may be generally attractive to wildcaught and first-generation midges, although responses were lost in later generations of midges; even though the numbers of Forcipomyia sp. we were able to test were very low, 4 out of 6 selected the odor over the control. We did not observe any attraction to a partial synthetic blend we created to replicate this odor. This suggests that in the field the odor of the cacao flower will play a role in enabling flower-visiting midges to locate flowers and thus facilitate pollination. All three species we tested (D. borgmeieri, C. paraensis, Forcipomyia sp.), are known cacao flower visitors (Winder 1977; Young 1986) and so their behavior has implications in cocoa production.

Volatile compounds collected from cacao flowers in this study were shown to consist of a suite of saturated and unsaturated hydrocarbons, as reported by Erickson et al. (1987) and Young and Severson (1994). These authors identified the major components as 1-pentadecene and 1heptadecene, whereas we identified those in our samples conclusively as (Z)-7-pentadecene and the homologous (Z)-8heptadecene. The 1-isomers could not be detected. Erickson et al. (1987) obtained samples by steam distillation of cut flowers from another Trinitario variety, whereas our samples were collected by direct aeration of flowers on the stem. It is possible that the resulting samples obtained by Erickson et al. (1987) were different from ours, but they reported identification of compounds only by comparison of their mass spectra with those in the mass spectra database, and this is insufficient evidence to ascertain the position of unsaturation. It thus seems possible that the compounds were misidentified and the errors were promulgated in the subsequent paper by Young and Severson (1994).

Other significant components in the volatile collections were the saturated $n$-alkanes tridecane, tetradecane and pentadecane. Minor components included mono-unsaturated 5-tridecene, a homologue of the two major monoenes, and 6and 7-tetradecenes and 8- and 7-hexadecenes. In the absence of the synthetic compounds, it was not possible to assign the configurations of the minor, mono-unsaturated components of cacao flower volatiles, but it is likely to be $(Z)$ in comparison with that of the major mono-unsaturated compounds.

The major components, $(Z)-7$-pentadecene and (Z)-8heptadecene, are probably derived biosynthetically by decarboxylation of palmitoleic acid ((Z)-9-hexadecenoic acid) and oleic acid ((Z)-9-octadecenoic acid), respectively, a previously reported plant biosynthetic pathway (Jurenka 2004). The other mono-unsaturated hydrocarbons could be derived biosynthetically by similar decarboxylations.

Other minor components were a di-unsaturated 16-carbon and a di-unsaturated 17-carbon atom compound. The latter had GC retention indices and mass spectrum consistent with it being (Z,Z)-6,9-heptadecadiene, and the 16-carbon homolog is thus probably $(Z, Z)-6,9$-hexadecadiene. These could be derived biosynthetically by successive decarboxylations of linoleic acid $((Z, Z)-9,12$-octadecadienoic acid). A triunsaturated 17-carbon compound was also detected with identical GC retention indices and mass spectrum to those of (Z,Z,Z)-3,6,9-heptadecatriene, which could be derived biosynthetically by decarboxylation of linolenic acid $((Z, Z, Z)$ 9,12,15-octadecatrienoic acid) via known plant biosynthetic pathways.

(Z)-8-Heptadecene was reported as a component of the fragrance of flowers of orchids of the Stanhopea genus (Asparagales: Orchidaceae) by Whitten and Williams (1992), where it was accompanied by saturated hydrocarbons as well as a wide range of different terpenoid and phenylpropanoid compounds. A blend of hydrocarbons and terpenoids was also identified in volatiles collected from flowers of Yucca glauca (Asparagales: Asparagaceae) by Svensson et al. (2011) and, more recently, Tröger et al. (2019) reported flowers of $Y$. reverchonii produced a blend of saturated and unsaturated hydrocarbons only. This blend was similar to that reported here from cacao flowers with the major component identified as (Z)-8-heptadecene, accompanied by $(Z, Z)-6,9$-heptadecadiene and heptadecane as minor components (Tröger et al. 2019). These authors admitted that they had wrongly identified the heptadecene as 1-heptadecene in their earlier paper (Svensson et al. 2011).

Our synthetic blend consisted of the major components tridecane, pentadecane, $(Z)$-7-pentadecene and $(Z)-8$ heptadecene. We tested it at two different concentrations, but neither mediated attraction behavior from the midges. This indicates that the major components alone are not sufficient for eliciting the directed movement towards an odor source that we observed from the natural odor blend. It is likely that minor components are necessary for flower recognition. This has been reported in a few other study systems of pollinatorplant interactions, especially with specialist and non-bee pollinators such as fig wasps (Chen and Song 2008) or the role of DMDS and dimethyl trisulfide (DMTS) as part of an overall more complex blend in mediating attraction by flies versus wasps in African Eucomis species (Shuttleworth and Johnson 2010). We anticipate that the dienes and triene detected in the cacao floral odor blends could be important, either singly or in combination with major components, in facilitating midge attraction. These were not available for 
Fig. 2 Cocoa midge preferences by species tested, for natural cacao flower odor and synthetic cacao flower odor blend (SCFO) in a Y-tube olfactometer, with solvent control in the opposing arm. Figures on bars indicate sample size. $*$ indicates $p<0.05$ significant preference

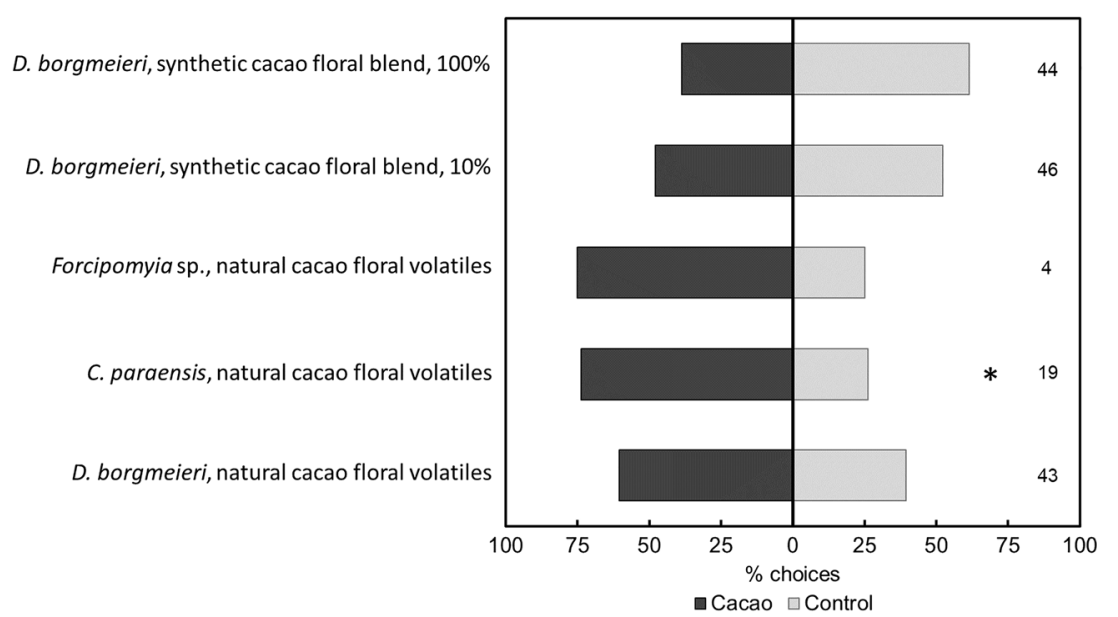

testing in this study, but dienes are known to mediate behavior in other Diptera such as Drosophila melanogaster Meigen, where 7,11-dienes mediate mating behavior (Marcillac and Ferveur 2004).

The odor composition of cacao flowers contains compounds more typical of insect cuticle, waxes and pheromones (Blomquist and Jackson 1979). (Z)-7-pentadecene was isolated from ant Dufour glands, along with tridecane, tetradecane, pentadecane, and heptadecanes and heptadecenes (Billen et al. 1986), and (Z)-8-heptadecene and analogous saturated hydrocarbons were found in the anal secretions of Holothrips species (Suzuki et al. 2004). This suggests a possible connection to other aspects of midge's life history. The relationship between cocoa midges and cacao is of particular note because they interact with their plant in different ways at different lifestages, the larvae developing in the rotting pods of the tree and the adults feeding in the flowers. However, adult females of many Ceratopogonidae genera (including Forcipomyia and Culicoides) also feed on blood or insect haemolymph. Volatiles associated with insects (cuticle, frass or pheromones) often function as kairomones for parasitoids and ectoparasites (Steidle et al. 2003). As the components of cacao floral odor resemble many insect kairomones, the blend may exploit preexisting biases in the olfactory systems of midges related to host-feeding. The key volatiles may also have biological relevance for Ceratopogonidae, in conspecific interactions; as oviposition cues, e.g. those associated with certain bacterial biofilms on which midge larvae feed (Besemer and Soria 1978; Saunders 1959); or indicating other sources of nutrition for adult female midges. However, there remains insufficient data either about cacao pollination in natural habitats, or about cocoa midge biology and behavior, to conclude anything with certainty. Electroantennography (EAG) was attempted with D. borgmeieri and Forcipoymia sp. in order to further explore their test antennal responses to the different odor components, but it was not possible to obtain reliable results due to their small size and presence of moving mouthparts.
The study provides several important new advances. Firstly, we demonstrate that rearing cocoa midge potential pollinators (D. borgmeieri) over several generations in a laboratory is possible. This invites future research areas on the behavior and physiology of this species. It also means that mass-rearing of this species for managed pollination services may one day become possible. Secondly, we have updated our knowledge of the volatiles produced by flowers of this major crop.

By improving our understanding the chemical ecology of cacao pollination we are better placed to understand the poor pollination rates in many cacao plantations and relate this to midge-cacao interactions. Cacao pollination is understudied, with little known about the plant-insect interactions involved. Even less is known about pollination of wild trees (Chumacero de Schawe et al. 2018) in its native range (Amazon basin) (Richardson et al. 2015), although the importance of small Hymenoptera on wild cacao may have been underestimated in the past, compared to agroforestry systems where Diptera are usually anticipated to be most important (Entwistle 1972; Winder 1978a). The information we have acquired in this study can be further expanded and perhaps even used in future breeding programs.

There is increasing global interest developing in precision pollination systems, including via optimizing commercially reared pollinators (Molet et al. 2009), integrated pollination and pest management systems (Karise et al. 2016; Smagghe et al. 2013) and deployment of agricultural technologies in improvement of pollination (Olombria 2019). This may open up future opportunities to use an improved understanding of non-bee pollinators in commercial settings to improve crop production, especially in high-value crops with growing global demand such as cacao.

Acknowledgements We acknowledge funding from the AfricanCaribbean-Pacific Group of States through the ACP Caribbean and Pacific Research Programme for Sustainable Development "Optimisation of cocoa pollination for increased yield and income generation" project FED/2011/290-490. We thank Mr. Jude Lee Sam, the 
Ministry of Agriculture, Cocoa Research Section of Trinidad and Tobago, the Cocoa Industry Board of Jamaica and Mr. Errol Williamson for permission to sample on their sites, Mr. Vernon Barrett and Mrs. Euphemia Cazoe for project guidance and coordination, and Ms. Raeesah Sahibdeen for technical assistance. We thank two anonymous referees for their comments on the manuscript.

Authors' Contributions PCS, SRB and SEJA devised the program of work; SEJA, SJF, DRH, DIF, DPB, SRB and PCS developed the protocols and experimental designs; SEJA, SJF, DRH, DIF, GBP and PCS performed the experiments and data collection; PB, LG, GBP and SJF coordinated the fieldwork; SEJA, DIF, DRH and GRS analyzed the data and specimens; SEJA, DRH, DIF, DPB, SRB and PCS wrote the manuscript text. All authors contributed critically to the drafts and gave final approval for publication.

Open Access This article is distributed under the terms of the Creative Commons Attribution 4.0 International License (http:// creativecommons.org/licenses/by/4.0/), which permits unrestricted use, distribution, and reproduction in any medium, provided you give appropriate credit to the original author(s) and the source, provide a link to the Creative Commons license, and indicate if changes were made.

\section{References}

Aneja M, Gianfagna T, Ng E (1999) The Roles of Abscisic Acid and Ethylene in the Abscission and Senescence of Cocoa Flowers. Plant Growth Regul 27:149-155. https://doi.org/10.1023/A: 1006153502897

Arnold SEJ, Faruq S, Savolainen V, McOwan PW, Chittka L (2010) FReD: The Floral Reflectance Database - A Web Portal for Analyses of Flower Colour. PLoS One 5:e14287. https://doi.org/ 10.1371/journal.pone.0014287

Arnold SEJ et al (2018) The Significance of Climate in the Pollinator Dynamics of a Tropical Agroforestry System. Agric Ecosyst Environ 254:1-9. https://doi.org/10.1016/j.agee.2017.11.013

Besemer H, Soria S (1978) Laboratory Rearing of Forcipomyia spp. midges (Diptera, Ceratopogonidae), 1: Adult Feeding, Larval Feeding and Copulation Trials; A Revision of Saunders Method of Rearing. Rev Theobroma (Brazil) 8:43-59

Billen JPJ, Evershed RP, Attygalle AB, Morgan ED, Ollett DG (1986) Contents of Dufour Glands of Workers of Three Species of Tetramorium (Hymenoptera: Formicidae). J Chem Ecol 12:669685. https://doi.org/10.1007/BF01012101

Blackwell A, Dyer C, Luntz AJ, Wadhams L, Mordue W (1994) Field and Laboratory Evidence for a Volatile Pheromone Produced by Parous Females of the Scottish Biting Midge, Culicoides impunctatus. Physiol Entomol 19:251-257

Blomquist GJ, Jackson LL (1979) Chemistry and Biochemistry of Insect Waxes. Prog Lipid Res 17:319-345. https://doi.org/10.1016/00796832(79)90011-9

Borkent A, Spinelli GR (2007) Neotropical Ceratopogonidae (Diptera: Insecta) vol 4. Aquatic biodiversity in Latin America. Pensoft Publishers, Sofia, Bulgaria

Brew AH (1987) The effect of colours and specific features of floral parts on the pollination of cocoa by ceratopogonid midges in Ghana. Proceedings of the 10th International Cocoa Research Conference, 1987, Santa Domingo. Publisher: Cocoa Producers Alliance, Lagos. pp. $307-310$

Buser HR, Arn H, Geurin P, Rauscher S (1983) Determination of Double Bond Position in Monounsaturated Acetates by Mass Spectrometry of Dimethyldisulfide Adducts. Anal Chem 55:818-822
Byers KJRP, Bradshaw HD, Riffell JA (2014a) Three Floral Volatiles Contribute to Differential Pollinator Attraction in Monkeyflowers (Mimulus). J Exp Biol 217:614-623. https://doi.org/10.1242/jeb. 092213

Byers KJRP, Vela JP, Peng F, Riffell JA, Bradshaw HD Jr (2014b) Floral Volatile Alleles can Contribute to Pollinator-Mediated Reproductive Isolation in Monkeyflowers (Mimulus). Plant J 80:1031-1042. https://doi.org/10.1111/tpj.12702

Carlson DA, Roan CS, Yost RA, Hector J (1989) Dimethyl Disulfide Derivatives of Long Chain Alkenes, Alkadienes, and Alkatrienes for Gas Chromatography/Mass Spectrometry. Anal Chem 61: 1564-1571. https://doi.org/10.1021/ac00189a019

Chen C, Song Q (2008) Responses of the pollinating wasp Ceratosolen solmsi marchali to odour variation between two floral stages of Ficus hispida. J Chem Ecol 34:1536-1544. https://doi.org/10.1007/ s10886-008-9558-4

Chumacero de Schawe C, Kessler M, Hensen I, Tscharntke T (2018) Abundance and Diversity of Flower Visitors on Wild and Cultivated Cacao (Theobroma cacao L.) in Bolivia. Agrofor Syst 92:117-125. https://doi.org/10.1007/s10457-016-0019-8

Dafni A, Lehrer M, Keyan PG (1997) Spatial Flower Parameters and Insect Spatial Vision. Biol Rev 72:239-282

Dyer AG, Whitney HM, Arnold SEJ, Glover BJ, Chittka L (2006) Bees Associate Warmth with Floral Colour. Nature 442:525-525. https:// doi.org/10.1038/442525a

Entwistle PF (1972) Pests of Cocoa. Tropical Agriculture Series, Longman, London, UK

Erickson BJ, Young AM, Strand MA, Erickson EH (1987) Pollination Biology of Theobroma and Herrania (Sterculiaceae): II. Analyses of Floral Oils. Int J Trop Insect Sc 8:301-310

Forbes SJ, Northfield TD (2017) Increased Pollinator Habitat Enhances Cacao Fruit Set and Predator Conservation. Ecol Appl 27:887-899. https://doi.org/10.1002/eap.1491

Frimpong EA, Gordon I, Kwapong PK, Gemmill-Herren B (2009) Dynamics of Cocoa Pollination: Tools and Applications for Surveying and Monitoring Cocoa Pollinators. Int J Trop Insect Sc 29:62-69. https://doi.org/10.1017/s1742758409990117

Groeneveld JH, Tscharntke T, Moser G, Clough Y (2010) Experimental Evidence for Stronger Cacao Yield Limitation by Pollination than by plant Resources. Perspect Plant Ecol 12:183-191. https://doi.org/ 10.1016/j.appees.2010.02.005

Jurenka R (2004) Insect Pheromone Biosynthesis. In: Schulz S (ed) The chemistry of Pheromones and other Semiochemicals I. Top Curr Chem vol 239. Springer, Berlin Heidelberg New York, pp 97-132

Karise R et al (2016) Reliability of the Entomovector Technology using Prestop-Mix and Bombus terrestris L. as a Fungal Disease Biocontrol Method in Open field. Sci Rep 6:31650. https://doi.org/ 10.1038/srep31650

Kaufmann T (1973) Preliminary Observations on Cecidomyiid Midge and Its Role as a Cocoa Pollinator in Ghana. Ghana J Agric Sci 6: 193-198

Kaufmann T (1975) Cocoa pollination by males of Forcipomyia squamipennis (Diptera: Ceratopogonidae) in Ghana. Thus Trop Agric 52:71-74

Marcillac F, Ferveur J-F (2004) A set of Female Pheromones Affects Reproduction Before, During and After Mating in Drosophila. J Exp Biol 207:3927

Molet M, Chittka L, Raine NE (2009) Potential Application of the Bumblebee Foraging Recruitment Pheromone for Commercial Greenhouse Pollination. Apidologie 40:608-616

O'Doherty DC, Zoll JJK (2012) Forcipomyia hardyi (Diptera: Ceratopogonidae), A Potential Pollinator of Cacao (Theobroma cacao) Flowers in Hawaii. Proc Hawaiian Entomol Soc 44:79-81

Olombria LTD. (2019) Future Systems for Pollination, using Flies and Precision Agri-Tech for a Changing World. http://www. flypollination.com/. Accessed 19/02/19 2019 
Raguso R (2008) Wake Up and Smell the Roses: The Ecology and Evolution of Floral Scent. Annu Rev Ecol Evol S 39:549-569. https://doi.org/10.1146/annurev.ecolsys.38.091206.095601

Richardson JE, Whitlock BA, Meerow AW, Madriñán S (2015) The Age of Chocolate: A Diversification History of Theobroma and Malvaceae. Front Ecol Evol 3:120. https://doi.org/10.3389/fevo. 2015.00120

Sampayan T (1966) Flower Biology, Fruiting Habit and Compatibility Relationship in Cacao. Philippine J Plant Ind 31:193-201

Saunders LG (1959) Methods for Studying Forcipomyia midges, with Special Reference to Cacao-Pollinating Species (Diptera: Ceratopogonidae). Can J Zool 37:33-51. https://doi.org/10.1139/ z59-005

Schiestl FP (2010) The Evolution of Floral Scent and Insect Chemical Communication. Ecol Lett 13:643-656. https://doi.org/10.1111/j. 1461-0248.2010.01451.x

Shuttleworth A, Johnson SD (2010) The Missing Stink: Sulphur Compounds can Mediate a Shift Between Fly and Wasp Pollination Systems. P Royal Soc B-Biol Sci 277:2811-2819. https://doi.org/10.1098/rspb.2010.0491

Smagghe G, Meeus I, De Meyer L, Mommaerts V (2013) Safety and Acquisition Potential of Metarhizium anisopliae in Entomovectoring with Bumble Bees, Bombus terrestris. J Econ Entomol 106:277-282. https://doi.org/10.1603/EC12332

Steidle JLM, Steppuhn A, Ruther J (2003) Specific Foraging Kairomones used by a Generalist Parasitoid. J Chem Ecol 29:131-143. https:// doi.org/10.1023/A:1021932731350

Stewart-Jones A, Poppy GM (2006) Comparison of Glass Vessels and Plastic Bags for Enclosing Living Plant Parts for Headspace Analysis. J Chem Ecol 32:845-864. https://doi.org/10.1007/ s10886-006-9039-6

Suzuki T, Haga K, Tsutsumi T, Matsuyama S (2004) Analysis of anal secretions from phlaeothripine thrips. J Chem Ecol 30:409. https:// doi.org/10.1023/B:JOEC.0000017985.89897.c3
Svensson GP, Pellmyr O, Raguso RA (2011) Pollinator Attraction to Volatiles from Virgin and Pollinated Host Flowers in a Yucca/ Moth Obligate Mutualism. Oikos 120:1577-1583

Tröger A, Svensson GP, Altohoff DM, Segraves KA, Raguso RR, Francke W (2019) The Pattern of Straight Cain Hydrocarbons Released by Yucca flowers (Asparagaceae). J Chem Ecol 45:46-49

van der Klis F, van den Hoorn MH, Blaauw R, van Haveren J, van Es DS (2011) Oxidative Decarboxylation of Unsaturated Fatty Acids. Eur J Lipid Sci Technol 113:562-571

van Kleunen M, Nänni I, Donaldson JS, Manning JC (2007) The Role of Beetle Marks and Flower Colour on Visitation by Monkey Beetles (Hopliini) in the Greater Cape Floral Region, South Africa. Ann Bot 100:1483-1489

Whitten WM, Williams NH (1992) Floral Fragrances of Stanhopea (Orchidaceae). Lindleyana. 7:130-153

Winder JA (1977) Field Observations on Ceratopogonidae and other Diptera: Nematocera Associated with Cocoa Flowers in Brazil. B Entomol Res 67:57-63

Winder JA (1978a) Cocoa Flower Diptera: Their Identity, Pollinating Activity and Breeding Sites. Pest Articles and News Summaries 24:5-18. https://doi.org/10.1080/09670877809414251

Winder JA (1978b) The Role of Non-Dipterous Insects in the Pollination of Cocoa in Brazil. B Entomol Res 68:559-574

Young AM (1986) Notes on the Distribution and Abundance of Midges (Diptera: Ceratopogonidae and Cecidiomyiidae) in Some Central America Cacao Plantations. Brenesia 24:273-285

Young AM, Severson DW (1994) Comparative Analysis of Steam Distilled Floral Oils of Cacao Cultivars (Theobroma cacao L., Sterculiaceae) and Attraction of Flying Insects: Implications for a Theobroma Pollination Syndrome. J Chem Ecol 20:2687-2703. https://doi.org/10.1007/BF02036201

Young AM, Erickson BJ, Erickson EH (1989) Pollination Biology of Theobroma and Herrania (Sterculiaceae) 3. Steam-Distilled Floral Oils of Theobroma Species as Attractants to Flying Insects in a Costa Rican Cocoa Plantation. Int J Trop Ins Sc 10:93-98 